\title{
Caracterização Geológica, Petrográfica e Geoquímica dos Stocks Santa Maria e Monte Pedral, Domínio Canindé, Sistema Orogênico Sergipano
}

Geological, Petrographic and Geochemistry Characterization of the Santa Maria and Monte Pedral Stocks, Canindé Domain, Sergipano Orogenic System

\author{
H. S. Soares ${ }^{1,2^{*}} ;$ C. S. Sousa ${ }^{1,2} ;$ H. Conceição ${ }^{2,3} ;$ M. L. S. Rosa $a^{2,3}$ \\ ${ }^{1}$ Bolsista de Mestrado da CAPES
}

${ }^{2}$ Programa de Pós-Graduação em Geociências e Análise de Bacias da Universidade Federal de Sergipe (PGAB-UFS)

${ }^{3}$ Laboratório de Petrologia Aplicada à Pesquisa Mineral (LAPA). Galpão das Geociências, Complexo Laboratorial Multiusuário da UFS, Campus de São Cristóvão, 49100-000, São Cristóvão-SE, Brasil

*hiakan1@hotmail.com

(Recebido em 15 de setembro de 2017; aceito em 19 de janeiro de 2018)

\begin{abstract}
Os stocks Santa Maria (SSM) e Monte Pedral (SMP) são correlacionados à Suíte Intrusiva Serra do Catu (SISC) associada à Orogenia Brasiliana. Estes stocks são intrusivos nos terrenos do Domínio Canindé, Sistema Orogênico Sergipano, e localizam-se no extremo noroeste do Estado de Sergipe. Os dados petrográficos e geoquímicos sobre estas rochas indicam que elas são as mais evoluídas da SISC, têm granulação média a grossa, são isotrópicas e ocasionalmente porfiríticas. Enclaves máficos são abundantes. O SSM é formado por álcali-feldspato granito e hornblenda granito e o SMP por hornblenda quartzo monzonito e hornblenda granito. Os dados geoquímicos indicam que as rochas são shoshoníticas e apresentam assinatura de magmatismo de arco e posicionados em período pós-orogênico.

Palavras-chave: Petrografia, Geoquímica, Suíte Intrusiva Serra do Catu
\end{abstract}

The Santa Maria (SSM) and Monte Pedral (SMP) stocks are correlated to the Serra do Catu Intrusive Suite (SISC), positioned in Brazilian Orogeny. These stocks are intrusive in the Canindé domain of the Sergipano Orogenic System, located in the extreme northwest of the Sergipe State. The petrographic and geochemical data on these rocks indicate that they have medium to coarse granulation, mafic enclaves are abundant, are isotropic, occasionally porphyritic, and are the most evolved terms of SISC. The SSM is formed by alkalifeldspar granite and hornblenda granite. and the SMP by hornblende quartz monzonite and hornblende granite. The geochemical data show that the rocks are shoshonitics and have a post-orogenic magmatism signature.

Keywords: Petrography, Geochemistry, Serra do Catu Intrusive Suite

\section{INTRODUÇÃ̃o}

O Sistema Orogênico Sergipano (SOS) resulta da colisão entre dois terrenos distintos [1]: Cráton do São Francisco, localizado ao sul, e o Maciço Pernambuco Alagoas, localizado a norte. Associado a essa colisão neoproterozoica tem-se amplo plutonismo [1,2]. Eventos posteriores nos terrenos deste orógeno expuseram níveis crustais que permitem o acesso às câmaras magmáticas (stocks e batólitos).

Este trabalho apresenta e discute os resultados dos estudos geológico, petrográfico e geoquímico obtidos para os stocks Santa Maria (SSM) e Monte Pedral (SMP), que se localizam no Domínio Canindé, situado no extremo norte do Estado de Sergipe (Figura 1). Esses stocks são considerados pela literatura como correspondentes ao magmatismo Tipo Serra do Catu $[3,4,5]$ e, mais recentemente, como pertencente à Suíte Intrusiva Serra do Catu (SISC) [6].

A SISC é constituída por sienitos, monzonitos, granitos e álcali-feldspato granitos e os dados geoquímicos mostram afinidade com a Série Shoshonítica [3, 4, 5, 6]. A SISC ocorre nos domínios Poço Redondo e Canindé, localizados no extremo norte do Estado de Sergipe. 


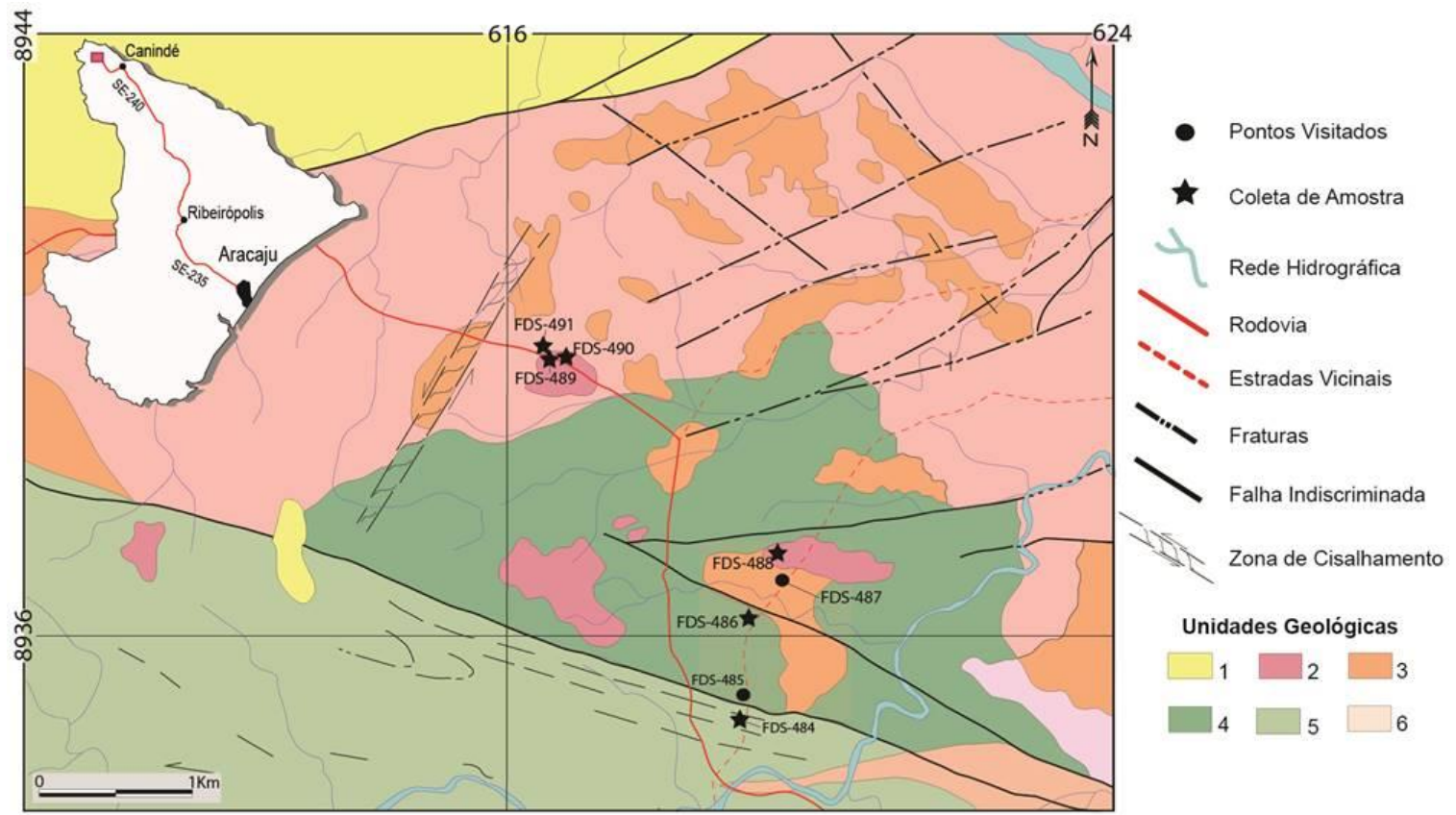

Figura 1: Esboço geológico de setor do Domínio Canindé onde ocorrem os stocks estudados, após os trabalhos executados pelo Serviço Geológico do Brasil [3]. O Stock Monte Pedral corresponde ao ponto onde localizase a amostra FDS-488 e o Stock Santa Maria, as amostras FDS-489 e FDS-490. Coberturas Sedimentares (1); Suíte Intrusiva Serra do Catu (2); Suíte Intrusiva Xingó (3); Suíte Intrusiva Canindé (4); Complexo Canindé (5); Suíte Intrusiva Curralinho (6). O retângulo vermelho na imagem, que apresenta o contorno geográfico do Estado de Sergipe, corresponde a área de estudo.

\section{MATERIAL E MÉTODOS}

A pesquisa iniciou-se com o levantamento dos estudos existentes na região $[1,2,3,4,5,6,7,8$, $9,10,11,12,13,14,15,16$ e 17], ao qual integrou-se as informações disponíveis sobre a Suíte Intrusiva Serra do Catu, particularmente em Sergipe e na região de ocorrência dos stocks Santa Maria e Monte Pedral. A etapa seguinte foi a realização de missões de campo aos SSM e SMP com o objetivo de coletar dados geológicos (relações de contato entre os corpos ígneos e as rochas encaixantes, atitudes e feições estruturais, etc.) e amostras representativas de rochas desses stocks e de suas encaixantes.

Entre as amostras coletadas, foram selecionadas aquelas mais representativas para os estudos petrográfico e geoquímico. A preparação iniciou com a separação de três porções de cada rocha. Uma parte, para a confecção de lâmina delgada e delgada-polida. A confecção das lâminas foi realizada no Laboratório de Laminação da Superintendência de Salvador, do Serviço Geológico do Brasil (CPRM/SUREG SA). Quantidade semelhante de amostra foi arquivada na litoteca do Laboratório de Petrologia Aplicada à Pesquisa Mineral da Universidade Federal de Sergipe (LAPAUFS). A terceira parte da amostra foi britada para obtenção de fragmentos inferiores a $2 \mathrm{~cm}$. A britagem foi realizada utilizando-se o britador da marca Pavitest ${ }^{\circledR}$, modelo I-4198. O material britado foi quarteado até a obtenção de cerca de 100 gramas da amostra, a qual foi pulverizada até granulação inferior a 200\#. A pulverização foi feita em moinho de panela da marca Contenco ${ }^{\circledR}$, modelo I-4222, do Departamento de Geologia da UFS.

As descrições petrográficas das rochas foram realizadas no Laboratório de Petrografia e Metalografia do Condomínio de Laboratórios Multiusuários das Geociências (CLGeo-UFS). O microscópio trinocular com luz transmitida e refletida da marca Opton ${ }^{\circledR}$, modelo TNP-09NT foi utilizado. A estimativa do volume dos minerais das lâminas estudadas foi feita a partir da estimativa visual de 40 campos. A nomenclatura das rochas seguiu as recomendações da International Union Geology Sciencies [18]. Os conteúdos de anortita dos cristais de plagioclásio das rochas estudadas foram obtidos com espectrômetro de energia dispersiva (EDS) acoplado ao microscópio eletrônico de varredura (MEV) da marca Tescan ${ }^{\circledR}$, modelo Vega 3 LMU do CLGeo-UFS. 
Um volume de $40 \mathrm{~g}$ de pó de amostras dos stocks e de encaixantes foi enviado ao Acme Laboratoire Ltda, no Canadá, para a obtenção de análises geoquímicas. Os elementos maiores foram dosados utilizando-se ICP-OES e os elementos-traço foram dosados com ICP-MS.

Os dados geoquímicos obtidos foram tratados com o auxílio do software Geochemical Data Toolkit (GCDKit), versão 2.3 [19] e em planilhas Excel ${ }^{\circledR}$.

\section{RESULTADOS}

\subsection{Geológicos}

A área de estudo localiza-se no norte do Estado de Sergipe, no município de Canindé do São Francisco. Os stocks estudados são intrusivos no Domínio Canindé (Figura 1), nos terrenos da Suíte Intrusiva Canindé (Stock Monte Pedral) e da Suíte Intrusiva Curralinho (Stock Santa Maria). Estes dois stocks fazem parte de um conjunto de intrusões que truncam as estruturas resultantes da deformação regional [3] neste setor de Sergipe (Figura 1).

Os afloramentos estudados ocorrem como lajedos descontínuos, por vezes com diques centimétricos (Figura 2). Eles apresentam dimensões variadas, dominando afloramentos com aproximadamente $800 \mathrm{~m}^{2}$.

Em campo, as rochas estudadas são de coloração rósea a cinza claro (Figura 3), com granulação média a grossa, existindo tipos equigranulares e porfiríticos (Figuras 4, 5 e 6). As rochas exibem estrutura isotrópica, são ricas em enclaves (Figura 3), e contêm pegmatitos graníticos e sieníticos com anfibólio e biotita.

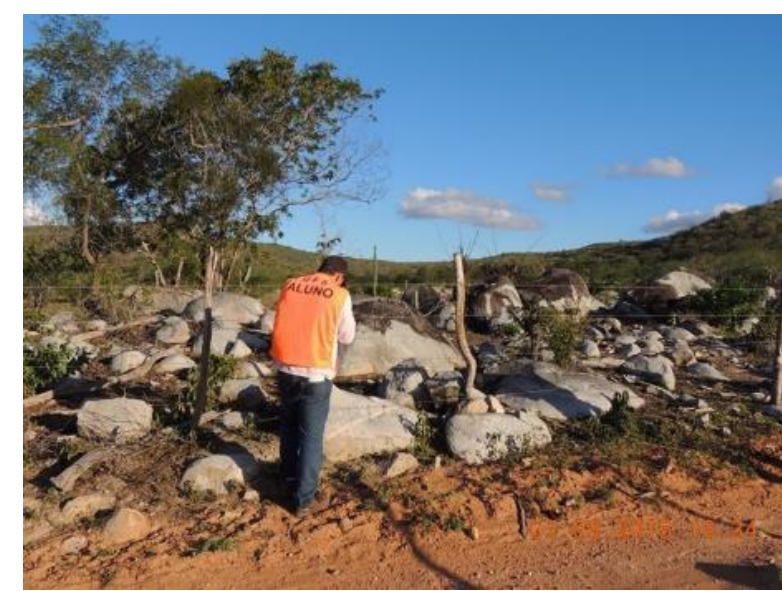

Figura 2: Visão geral dos afloramentos estudados. As rochas com tonalidade cinza correspondem a granitos e monzonitos. As faixas rosadas claras $e$ finas correspondem a diques graníticos.

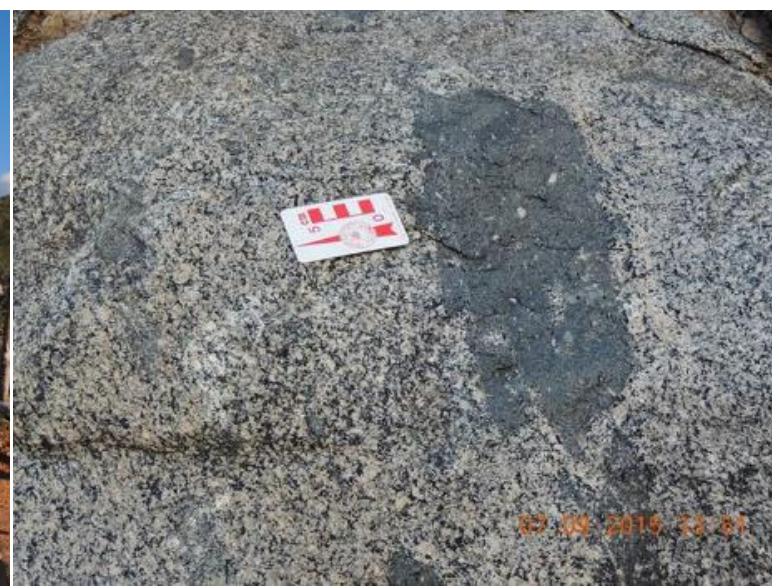

Figura 3: Textura dos monzonitos (cor cinza claro). A parte escura na imagem corresponde a enclave máfico microgranular. Os pontos brancos no interior do enclave correspondem a xenocristais de ortoclásio.

\subsection{Petrográficos}

No estudo petrográfico foram analisadas oito amostras, quatro delas pertencentes aos stocks Monte Pedral (FDS-488A e FDS-488B) e Santa Maria (FDS-489 e FDS-490), e as outras quatro são de rochas encaixantes (FDS-484, FDS-486A, FDS-486B e FDS-491). Os dados modais destas rochas são apresentados na tabela 1. As rochas dos stocks correspondem a hornblenda quartzo monzonito, hornblenda granito e álcali-feldspato granito. As rochas das Suíte Intrusiva Canindé e Suíte Intrusiva Curralinho, que constituem as encaixantes dos stocks, correspondem a metadiorito, metatonalito e biotita metatonalito gnáissico. 


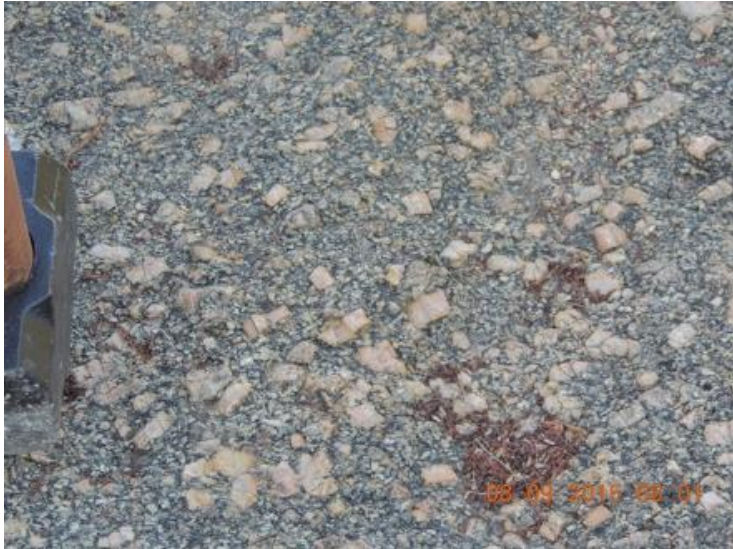

Figura 4: Textura porfirítica em monzonito, onde se destacam os fenocristais de ortoclásio euédricos (cor creme). É possivel visualizar alinhamento de fluxo magmático dos cristais de ortoclásio.

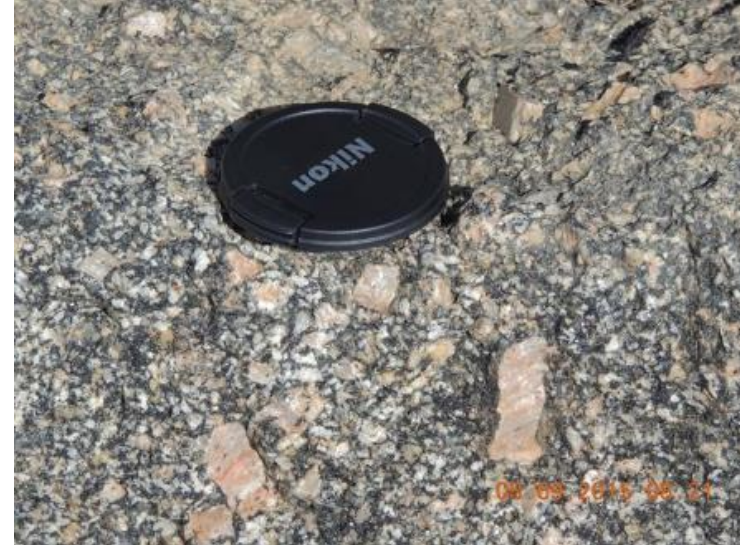

Figura 5: Detalhe da textura porfirítica em monzonito. Os fenocristais de ortoclásio (cor creme) apresentam tamanhos de até $3 \mathrm{~cm}$. Na matriz, as pontuações de cor branca correspondem a cristais de plagioclásio, e as escuras correspondem a cristais de anfibólio e biotita.

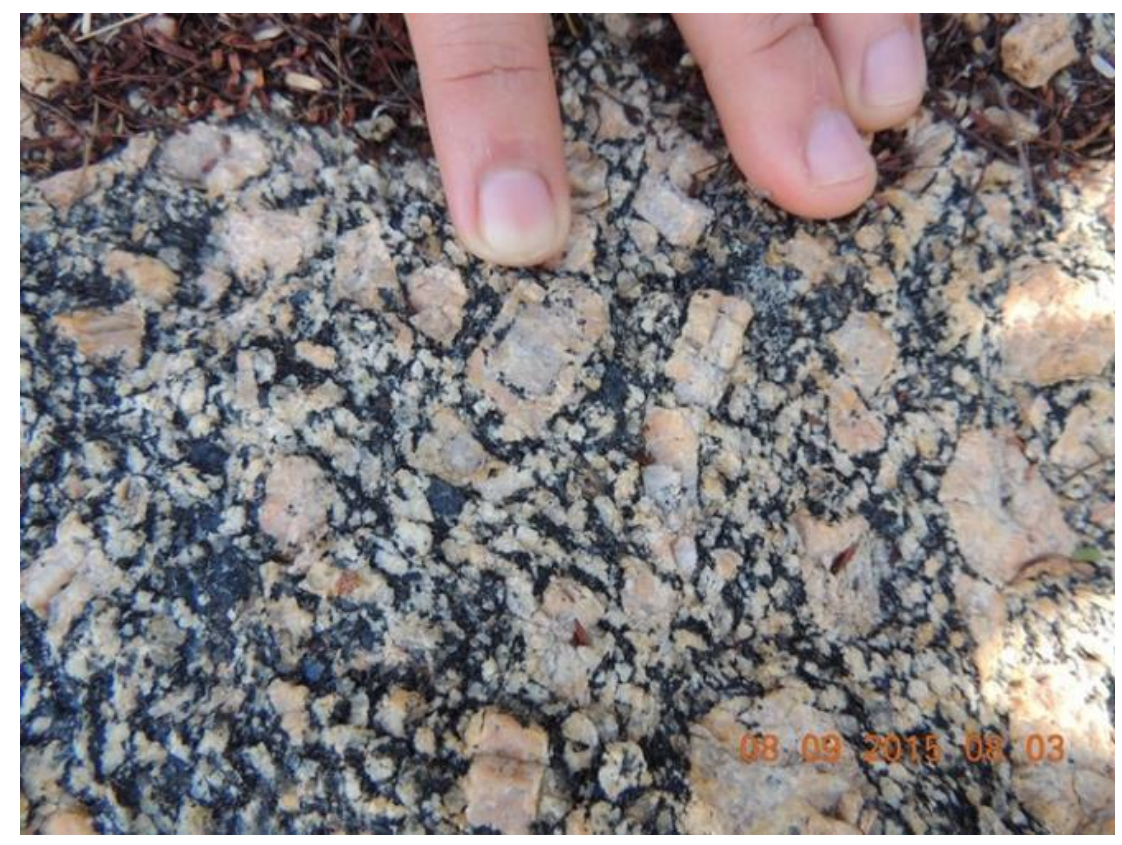

Figura 6: Detalhe de textura porfirítica em monzonito. Notar a zonação dos fenocristais de ortoclásio pertíticos (coloração creme) com as inclusões de biotita e o plagioclásio são os cristais de cor branca.

\section{A. Petrografia dos Stocks}

As feições petrográficas observadas nas rochas dos dois stocks estudados são muito semelhantes, refletindo, provavelmente, origem proveniente de magmas com composições e condições de cristalização próximas. Estas rochas, com cores róseas a cinza, apresentam granulação média a grossa (Figuras 5 e 6). A textura característica é inequigranular (Figuras 4, 5 e 6), nas quais a estrutura pode ser isotrópica ou anisotrópica com fluxo magmático ocasionalmente. A mineralogia essencial é constituída por: quartzo, feldspato alcalino, plagioclásio, biotita e hornblenda. Os minerais acessórios são: titanita, apatita, zircão e minerais opacos.

Cristais de feldspato alcalino (Figuras 7 e 8) ocorrem tanto como fenocristal (Figura 9) quanto participantes da matriz, indicando um longo período de cristalização deste mineral durante a evolução do magma. Os fenocristais são subédricos a euédricos (Figuras 4,5 e 6), pertíticos, e poiquilíticos (Figura 6). Existe maior frequência de geminação Carlsbad nos fenocristais, tendo-se 
na periferia aparecimento das geminações segundo as leis Albita-Periclina, indicando a inversão polimórfica. O feldspato alcalino muitas vezes exibe zoneamento composicional (Figura 7). Nos cristais da matriz, dominam as geminações Albita-Periclina. $\mathrm{O}$ feldspato alcalino possui inclusões de zircão, plagioclásio, hornblenda, biotita (Figura 6) e, raramente, apatita.

Tabela 1: Porcentagem em volume dos minerais nas rochas estudadas. Rochas dos stocks: Hornblenda quartzo monzonito (FDS-488A), Biotita Monzonito (FDS-488B), hornblenda granito (FDS-490), álcali-feldspato granito (FDS-489). Rochas encaixantes: metadioritos (FDS-486A e 486B), metatonalito (FDS-491), biotita metatonalito gnáissico (FDS-484). Minerais Opacos (M. Opacos). O percentual de anortita nos cristais de plagioclásio (\%An).

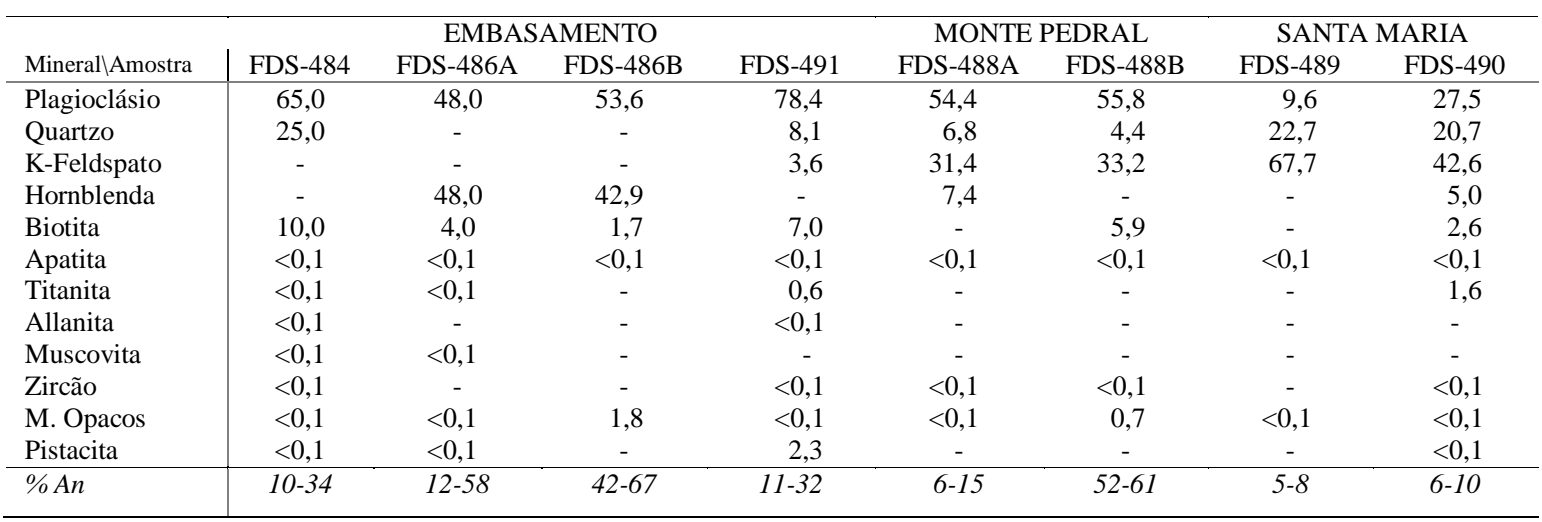

Os cristais de plagioclásio (Figuras 10 e 11) ocorrem tanto como fenocristais quanto na matriz. Os fenocristais $(0,44 \mathrm{~mm}$ a $1,11 \mathrm{~mm})$ apresentam composições com até $61,7 \%$ de anortita, exibem geminações (Albita e Albita-Carlsbad) e incluem cristais de apatita e titanita. É possível notar que os cristais de plagioclásio apresentam alteração diferenciada, que se marca por centro parcialmente alterado, contrastando com bordas sem alteração. Esta feição tem sido interpretada na literatura [20] como resultado de zoneamento composicional, refletindo instabilidades físico-químicas quando do resfriamento do magma. Albita $\left(\mathrm{An}_{6-10}\right)$ e oligoclásio $\left(\mathrm{An}_{11-28}\right)$ subédricos e anédricos ocorrem na matriz $(0,07 \mathrm{~mm}$ a $0,15 \mathrm{~mm})$ e não mostram feições de alteração importantes.

Os cristais de quartzo (Figuras 7, 8, 10 e 11) ocorrem na maioria das rochas como fenocristais e na matriz, em ambos os casos eles são anédricos e possuem extinção ondulante com intensidade moderada. Observou-se que eles possuem inclusões fluidas e de zircão que se distribuem de forma alinhadas, sendo esses alinhamentos dispostos de forma aleatória. Alguns cristais apresentam textura de mosaico, o que sugere recristalização.

Cristais de hornblenda subédricos ocorrem como matriz e como fenocristais. Exibem cor verde claro, com pleocroísmo variando de verde claro a verde escuro. Os tamanhos variam de $0,13 \mathrm{~mm}$ (matriz) a 5,3 mm (fenocristal). A hornblenda faz contatos curvos essencialmente com cristais de quartzo e plagioclásio.

A integração das diferentes informações obtidas no estudo petrográfico, permitiu inferir a sequência de cristalização dos minerais dos stocks Santa Maria e Monte Pedral como tendo sido iniciada com a cristalização de zircão, apatita, minerais opacos e titanita. Em seguida, foi possível cristalizar hornblenda e biotita. A cristalização do feldspato alcalino ocorre logo após a cristalização da labradorita, como atestam as inclusões de plagioclásio em fenocristais de feldspato alcalino pertítico. Nesse período, provavelmente, as existências de instabilidades físico-químicas importantes são responsáveis pelos múltiplos zoneamentos presentes em cristais de microclina pertítica. A microclina e o quartzo intersticiais são os últimos minerais a serem cristalizados no magma. Posteriormente, tem-se o período pós-magmático, provavelmente devido a percolação de fluidos hidrotermais nessas rochas, formando a clorita pela desestabilização de cristais de hornblenda e biotita. 


\section{B. Petrografia das Rochas do Embasamento}

As encaixantes dos stocks correspondem a rochas das suítes intrusivas Canindé e Curralinho. A nomenclatura adotada é precedida do termo meta (e.g. metadiorito e metatonalito), pois levou-se em conta a presença da foliação metamórfica regional nos vários afloramentos visitados.

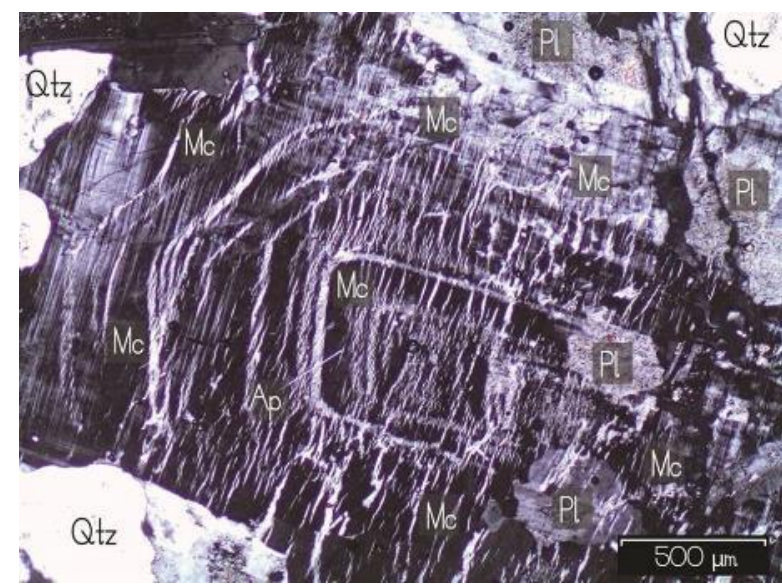

Figura 7: Cristal de microclina (Mc) pertítico apresentando textura de zonação química. Fase albita (branco) e fase potássica (tons de cinza). Quartzo (Qtz), plagioclásio $(\mathrm{Pl})$.

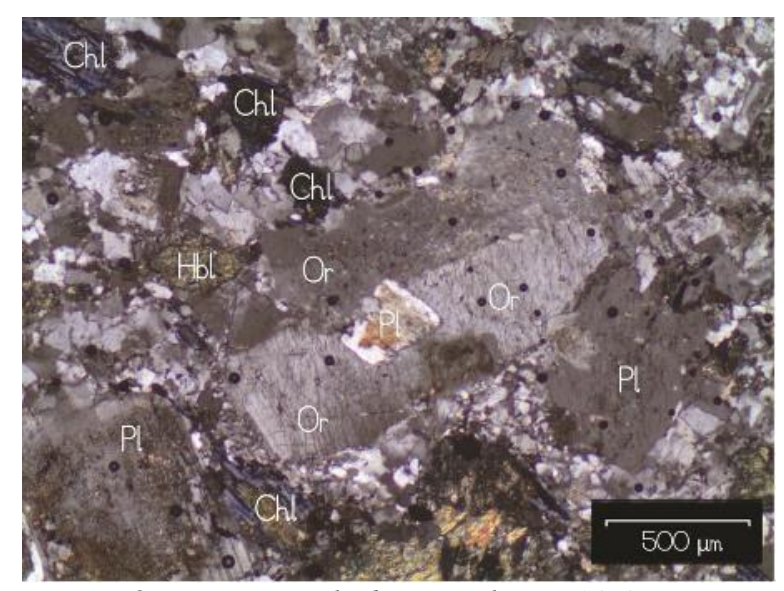

Figura 9: Fenocristal de ortoclásio (Or) pertítico, subédrico e poiquilítico. Nota-se que o plagioclásio $(\mathrm{Pl})$ ocorre incluso na porção central do ortoclásio, está saussuritizado e tem coroa albítica bem desenvolvida. Clorita (Chl) e hornblenda ( $\mathrm{Hbl})$

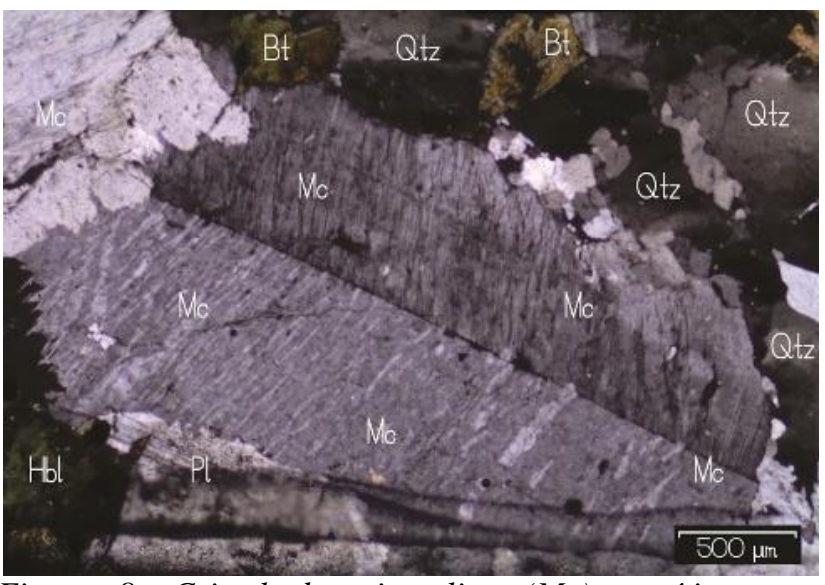

Figura 8: Cristal de microclina (Mc) pertítico com resquícios da geminação Carlsbad. A exsolução de albita apresenta-se como filetes brancos e a fase potássica em cinza. Biotita (Bt), hornblenda ( $\mathrm{Hbl})$.

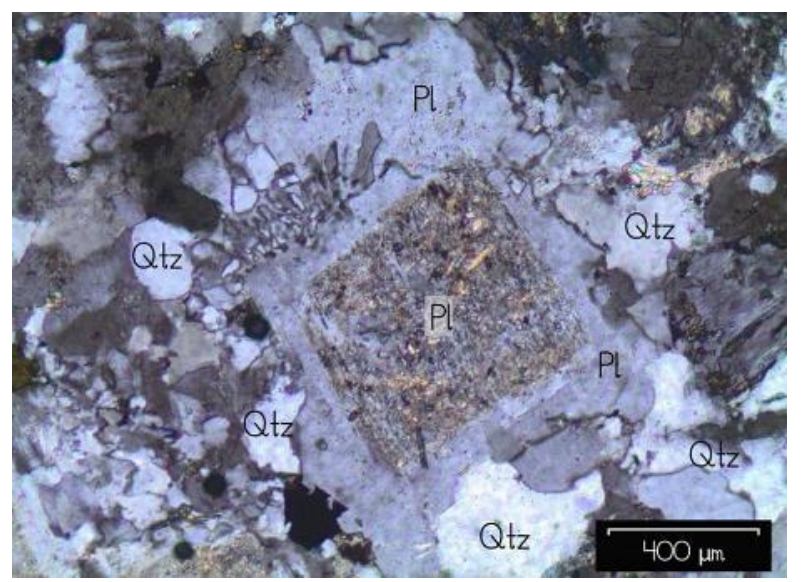

Figura 10: Fenocristal de plagioclásio (Pl) zonado, apresentando centro saussuritizado e borda sem alteração imerso em matriz com textura granofírica. 


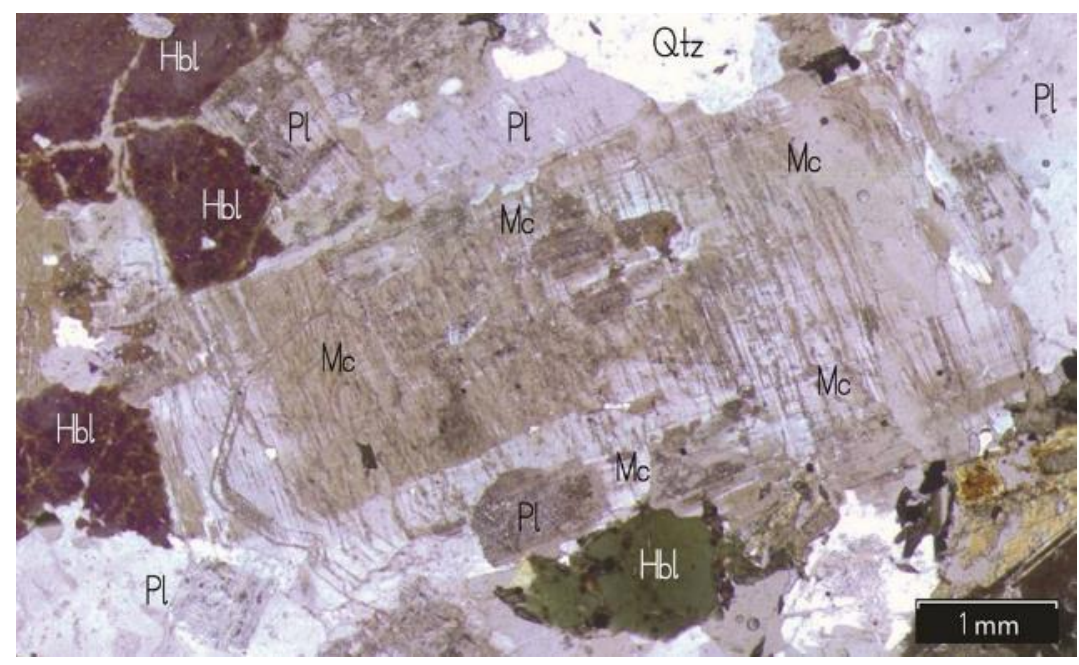

Figura 11: Imagem de fenocristal de microclina (Mc) pertítica e poiquilítica exibindo zoneamento múltiplo, em contato com hornblenda ( $\mathrm{Hbl})$, plagioclásio $(\mathrm{Pl})$ e quartzo $(\mathrm{Qtz})$.

\section{- Metadiorito:}

Estas rochas, ao microscópio, apresentam textura equigranular e são constituídas essencialmente por hornblenda, plagioclásio, quartzo e biotita. Os acessórios são minerais opacos, apatita, epídoto, titanita e muscovita. O conteúdo de minerais máficos dessas rochas varia de 51,9\% a 53,6\%.

Os cristais prismáticos de plagioclásio correspondem a oligoclásio, andesina e labradorita. Eles são subédricos (Figura 12) e geminados segundo as leis Albita e Albita-Carlsbad. Eles mostram contatos retos a curvos com cristais de hornblenda, minerais opacos e biotita. Cristais de hornblenda, apatita e minerais opacos, são inclusos no plagioclásio. Alguns cristais apresentam-se saussuritizados.

A hornblenda verde é o máfico dominante nessas rochas (Figura 12), sendo subédrica, normalmente com geminação simples e exibe pleocroísmo de verde claro a marrom. Em alguns cristais, percebe a mudança da cor verde a incolor do centro para a periferia, indicando zoneamento composicional de hornblenda para actinolita, que é interpretado como reequilíbrio para baixas temperaturas. A hornblenda inclui cristais de plagioclásio, minerais opacos e apatita.

Cristais de biotita marrom, com pleocroísmo em tons de marrom claro e escuro, são subédricos e incluem cristais de apatita e minerais opacos.

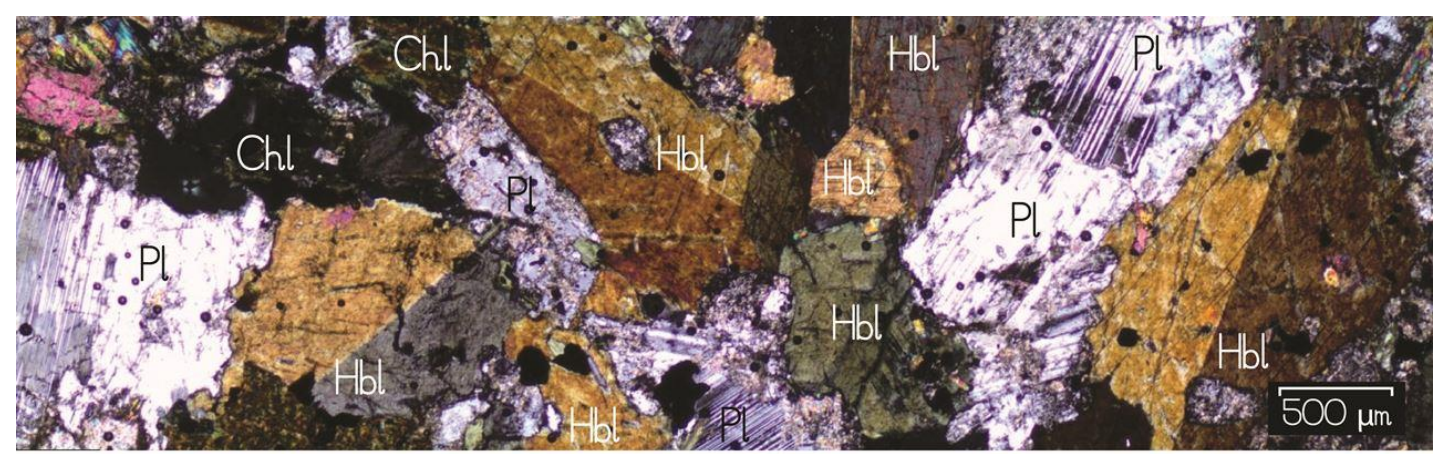

Figura 12: Textura geral dos metadioritos, mostrando cristais de hornblenda (Hbl) geminados e, por vezes, alterados para clorita (Chl). Cristais de plagioclásio (Pl) apresentando geminação Albita e quartzo (Qtz).

\section{- Metatonalito:}

Estas rochas apresentam foliação (Figura 13), textura inequigranular e equigranular. Por vezes, apresentam bandamento gnáissico que é marcado por bandas descontínuas mais ricas em cristais de biotita (Figura 13) e outra com maior volume de cristais de quartzo e plagioclásio. A mineralogia principal é constituída por plagioclásio (oligoclásio e andesina), microclina, ortoclásio, quartzo e epídoto. Os minerais acessórios são: titanita, apatita, zircão e minerais opacos. 
O plagioclásio ocorre preferencialmente subédrico, por vezes, euédrico. Ocasionalmente, exibe textura mirmequítica. Os cristais ocorrem tanto como fenocristal quanto na matriz, exibindo geminações segundo as leis Albita e Albita-Carlsbad e apresenta inclusões de apatita, zircão e titanita. Alguns cristais mostram saussuritização na porção central, sugerindo existência de zoneamento composicional.

Quartzo é anédrico e, por vezes, apresenta-se na rocha reunidos em aglomerados de cristais. Estes cristais exibem extinção ondulante em barra fraca e fazem contato com os cristais de plagioclásio, apatita e biotita. Ocorre inclusões de apatita acicular e inclusões fluidas alinhadas. Em certos locais da rocha, os cristais exibem textura mosaico e com contorno sigmóide que são interpretados como resultado de recristalização associada ao metamorfismo regional.

Biotita marrom é o mineral máfico mais abundante que ocorre subédrica e tem pleocroísmo variando de marrom claro ao marrom escuro. Além disso, faz contatos retilíneos com titanita, plagioclásio, quartzo, epídoto e minerais opacos. Ocasionalmente os minerais em contatos são encontrados como inclusões na biotita, exceto o plagioclásio e a pistacita. Alguns cristais alteraramse para clorita.

Os feldspatos alcalinos (Figura 13) são representados por microclina e ortoclásio, os quais são predominantemente subédricos, ocasionalmente ocorrendo euédrico ou anédrico, incluindo cristais de titanita, apatita, biotita e minerais opacos.

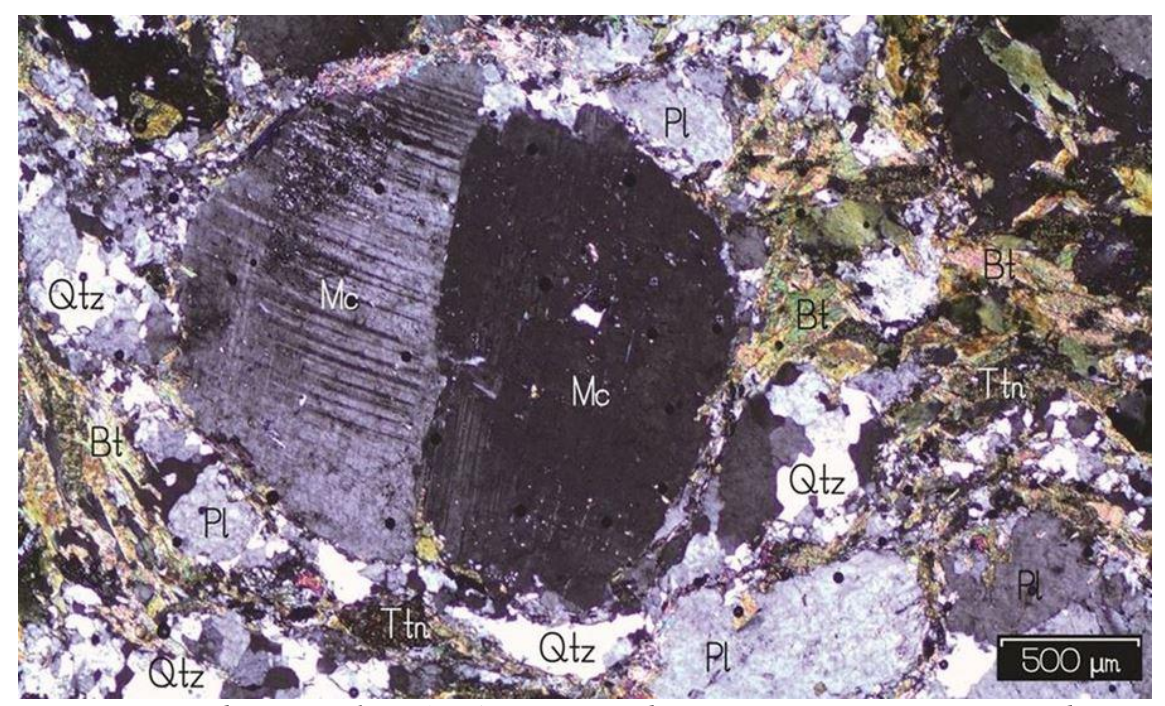

Figura 13: Fenocristais de microclina (Mc) rotacionados em contato com cristais de quartzo $(Q t z) e$ biotita (Bt). Nota-se a orientação dos cristais de biotita (Bt) contornando o cristal de microclina $(M c)$.

\subsection{Geoquímicos}

Neste trabalho, foram analisadas oito amostras, distribuídas entre as rochas dos stocks e encaixantes. Estes dados estão listados na tabela 2. Os dados geoquímicos de rochas representantes da Suíte Intrusiva Serra do Catu (SISC), disponíveis na literatura [3, 9 e 12] foram incorporadas nos digramas geoquímicos elaborados neste estudo.

As amostras dos stocks Santa Maria e Monte Pedral posicionam-se no diagrama TAS nos campos do granito, monzonito e granodiorito e alocam-se no campo subalcalino [21] (Figura 14). O total de álcalis das amostras dos stocks varia de 7,5\% a 9,2\% e a razão $\mathrm{K}_{2} \mathrm{O} / \mathrm{Na}_{2} \mathrm{O}$ varia de 1,1 a 2,0, revelando caráter potássico (Figura 14). Neste mesmo diagrama, observa-se que as rochas estudadas correspondem aos tipos mais evoluídos até o momento descritos para a Suíte Intrusiva Serra do Catu.

As rochas encaixantes no diagrama TAS posicionam-se nos campos alcalinos e subalcalinos (Figura 14). Elas posicionam-se no campo das rochas ultrabásicas e intermediárias e nos campos do gabro, monzonito e diorito (Figura 14). O total de álcalis varia de $3,4 \%$ a $9,1 \%$ e a razão $\mathrm{K}_{2} \mathrm{O} / \mathrm{Na}_{2} \mathrm{O}$ situa-se entre 0,2 a 0,7 , indicando caráter sódico. 
Tabela 2: Dados geoquímicos para as amostras estudadas. Perda a fogo (L.O.I.). Hornblenda quartzo monzonito (FDS-488A), Biotita Monzonito (FDS-488B), hornblenda granito (FDS-490), álcali-feldspato granito (FDS489). Rochas encaixantes: metadioritos (FDS-486A e 486B), metatonalito (FDS-491), biotita metatonalito gnáissico (FDS484).

\begin{tabular}{|c|c|c|c|c|c|c|c|c|}
\hline & \multicolumn{2}{|c|}{ MONTE PEDRAL } & \multicolumn{2}{|c|}{ SANTA MARIA } & \multicolumn{4}{|c|}{ EMBASAMENTO } \\
\hline & FDS-488A & FDS-488B & FDS-490 & FDS-489 & FDS-486A & FDS-486B & FDS-484 & FDS-491 \\
\hline $\mathrm{SiO}_{2}$ & 63,72 & 75,21 & 67,70 & 76,21 & 44,96 & 43,75 & 59,11 & 62,50 \\
\hline $\mathrm{Al}_{2} \mathrm{O}_{3}$ & 13,98 & 12,29 & 14,21 & 12,42 & 17,54 & 18,74 & 18,05 & 16,36 \\
\hline $\mathrm{Fe}_{2} \mathrm{O}_{3}$ & 4,99 & 2,16 & 3,41 & 1,04 & 12,75 & 13,70 & 5,26 & 5,97 \\
\hline $\mathrm{MnO}$ & 0,07 & 0,04 & 0,05 & 0,01 & 0,18 & 0,17 & 0,09 & 0,09 \\
\hline $\mathrm{Na}_{2} \mathrm{O}$ & 3,16 & 3,61 & 3,87 & 2,99 & 2,79 & 2,73 & 5,20 & 3,90 \\
\hline $\mathrm{K}_{2} \mathrm{O}$ & 4,78 & 3,95 & 5,37 & 5,96 & 0,95 & 0,68 & 3,94 & 2,55 \\
\hline $\mathrm{P}_{2} \mathrm{O}_{5}$ & 0,53 & 0,08 & 0,29 & 0,02 & 0,37 & 0,47 & 0,26 & 0,29 \\
\hline L.O.I. & 2,90 & 1,30 & 0,80 & 0,90 & 1,70 & 1,30 & 2,00 & 0,90 \\
\hline Total & 99,48 & 99,82 & 99,55 & 99,89 & 99,74 & 99,74 & 99,66 & 99,67 \\
\hline $\mathrm{Rb}$ & 116,1 & 147,1 & 203,2 & 181,5 & 18,0 & 8,8 & 122,4 & 67,6 \\
\hline
\end{tabular}

As relações entre $\mathrm{SiO}_{2}$ e $\mathrm{K}_{2} \mathrm{O}$ nas rochas dos stocks estudados permitem inferir que elas mostram afinidade com a Série Shoshonítica (Figura 15) e uma amostra (FDS-488B) se posiciona no campo da Série Cálcio-Alcalina de alto $\mathrm{K}_{2} \mathrm{O}$. As rochas do Stock Santa Maria (FDS-489 e FDS-490) mostram que o $\mathrm{K}_{2} \mathrm{O}$ aumenta com o aumento do $\mathrm{SiO}_{2}$, sugerindo que o feldspato alcalino e/ou biotita tenham cristalização tardia. O contrário parece ocorrer no Stock Monte Pedral (FDS-488A e FDS488B), sugerindo cristalização mais precoce de biotita e feldspato alcalino.

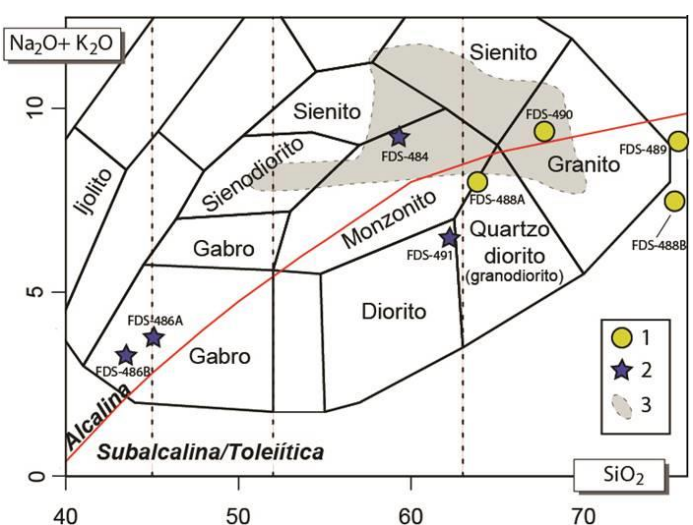

Figura 14: Diagrama que relaciona $\mathrm{Na}_{2} \mathrm{O}+\mathrm{K}_{2} \mathrm{O}$ versus $\mathrm{SiO}_{2}$, com os campos das rochas plutônicas de Cox e colaboradores [21]. Stocks estudados (1); rochas encaixantes (2); área delimitada com os dados disponíveis na bibliografia (3) [3, 9 e 12].

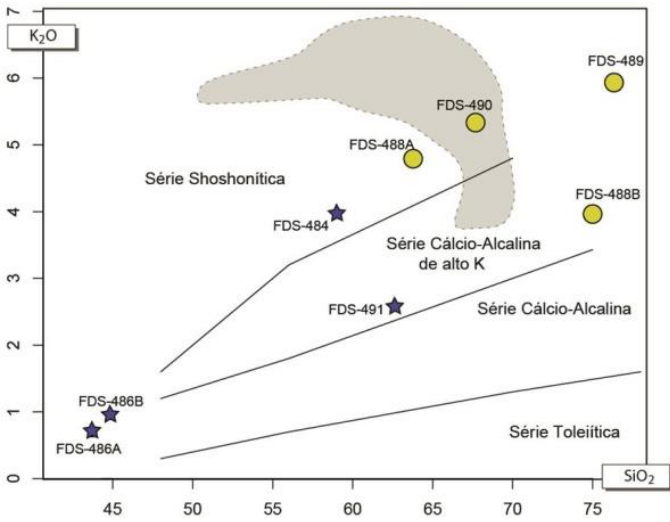

Figura 15: Diagrama $\mathrm{K}_{2} \mathrm{O}$ versus $\mathrm{SiO}_{2}$ de Peccerillo \& Taylor [22] com campos para rochas das suítes Toleiíticas, Cálcio-Alcalino de médio $\mathrm{K}_{2} \mathrm{O}$, Cálcio-Alcalino de alto $\mathrm{K}_{2} \mathrm{O} e$ Shoshonítica. Mesma legenda da figura 14.

As amostras dos corpos estudados mostram-se com uma variação entre os termos metaluminosos e peraluminosos (Figura 16). Percebe-se que elas mostram um crescimento na razão $\mathrm{Al}_{2} \mathrm{O}_{3} /(\mathrm{CaO}+$ $\mathrm{Na}_{2} \mathrm{O}+\mathrm{K}_{2} \mathrm{O}$ ) no diagrama de Shand [23]. Os dados da literatura sobre a Suíte Intrusiva Serra do Catu evidenciam que uma das características deste magmatismo é ser metaluminoso até fracamente peraluminoso.

Os conteúdos dos elementos-traços posicionam as rochas estudadas no diagrama de Pearce e colaboradores [24], no campo de magmas gerados em ambiente de arco-vulcânico (Figura 17), com exceção de uma amostra que se posiciona no campo dos magmas sincrônicos à colisão, o que pode indicar contaminação crustal. As amostras das encaixantes alocam-se igualmente no campo dos 
magmas gerados em ambiente de arco-vulcânico o que vem a reforçar a assinatura de arco para o magmatismo nesse setor do SOS.

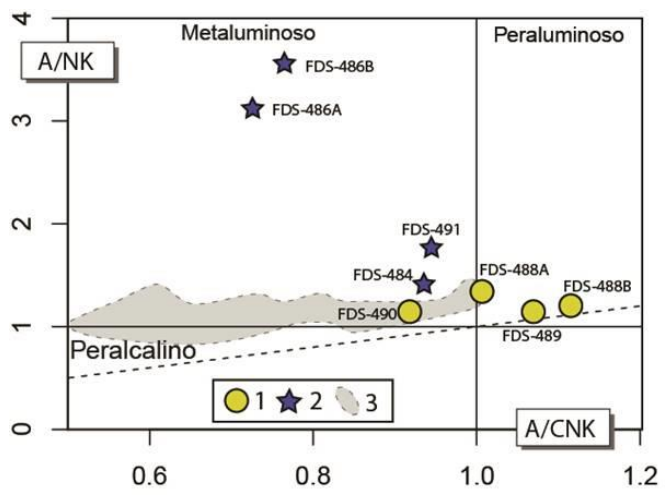

Figura 16: Diagrama em mols $A / N K$ versus $\mathrm{A} / \mathrm{CNK}$ [23]. $\mathrm{Al}_{2} \mathrm{O}_{3}(\mathrm{~A}), \mathrm{Na}_{2} \mathrm{O}(\mathrm{N}), \mathrm{K}_{2} \mathrm{O}(\mathrm{K})$ e $\mathrm{CaO}$ (C.) Stocks estudados (1); rochas encaixantes (2); dados disponíveis na bibliografia [3, 9 e 12] (3).

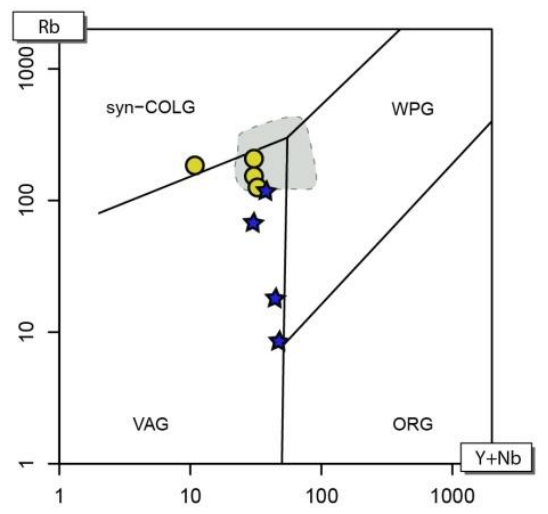

Figura 17: Diagrama $R b$ versus $Y+N b$ de Pearce e colaboradores [24] aplicado às rochas estudadas. Granitos de arco vulcânico (VAG), Granitos intraplaca (WPG), Granitos sincrônicos a colisão (SynCOLG) e Granitos de cadeia oceânica (ORG).

\section{CONCLUSÃO}

Os stocks Santa Maria e Monte Pedral são intrusivos em rochas das suítes intrusivas Canindé e Curralinho. Os stocks são formados por hornblenda quartzo monzonito, álcali-feldspato granito e hornblenda granito com coloração rósea clara a cinza, inequigranulares, ocasionalmente porfiríticos, e com granulação média a grossa.

Os principais minerais encontrados nas rochas dos stocks são plagioclásio, feldspato alcalino, hornblenda, biotita e quartzo. A mineralogia acessória é composta por apatita, titanita, zircão, allanita e minerais opacos. O conjunto de minerais encontrados não possui estruturas que indiquem a deformação das rochas. Além disso, possuem texturas típicas de rochas ígneas. Essas informações evidenciam e sugerem que as rochas dos stocks em questão foram intrusivas após a deformação regional.

Os dados geoquímicos permitiram identificar que são rochas que apresentam afinidades com a séries Shoshonítica e Cálcio-Alcalina de alto $\mathrm{K}_{2} \mathrm{O}$ e são metaluminosas a peraluminosas. As rochas dos stocks estudados são mais evoluídas do que as rochas da SISC disponíveis na literatura.

Os dados dos elementos traços nas rochas dos stocks as posicionaram no campo dos granitos formados em arcos vulcânicos, o que é coerente com os dados geotectônicos atribuídos para a evolução dessa parte do Sistema Orogênico Sergipano.

\section{AGRADECIMENTOS}

Os autores H.S. Soares e C.S. Sousa agradecem à Coordenação de Aperfeiçoamento do Pessoal do Nível Superior (CAPES) por suas bolsas de mestrado. Os autores expressam os seus agradecimentos ao Conselho Nacional de Desenvolvimento Científico e Tecnológico (CNPq) que deu suporte financeiro para alcançar os objetivos do trabalho (Processos $n^{\text {os }}$. 405387/2016-4, 370775/2012-0, 970018/2013-3 e 384713/2015-7). Este trabalho apresenta parte do trabalho de conclusão de curso do primeiro autor, que foi realizado junto ao Laboratório de Petrologia Aplicada à Pesquisa Mineral da Universidade Federal de Sergipe (LAPA-UFS). Agradecemos aos revisores pelo trabalho minucioso realizado. 


\section{REFERÊNCIAS BIBLIOGRÁFICAS}

1. Conceição JA, Rosa MLS, Conceição H. Sienogranitos leucocráticos do Domínio Macururé, Sistema Orogênico Sergipano, Nordeste do Brasil: Stock Glória Sul. Brazilian Journal of Geology. 2016 Mar;46(1):63-77, doi:10.1590/2317-4889201620150044.

2. Brito Neves BB. Regionalização geotectônica do precambiano nordestino [thesis]. São Paulo: Universidade de São Paulo; 1975. 207 p.

3. Santos RA, dos Souza JD de. Piranhas Folha SC-24-X-C-VI- Estado de Sergipe, Alagoas e Bahia. Brasília: DNPM/CPRM; 1988. 154 p.

4. Santos RA. Texto Explicativo do Mapa Geológico do Estado de Sergipe. Programa Levantamentos Geológicos Básicos do Brasil - PLGB. Geologia e recursos minerais do Estado de Sergipe. Escala 1:250.000. Brasília: CPRM/DIEDIG/DEPAT, CODISE; 2001.

5. Santos, RA. Mapa Geológico do Estado de Sergipe Programa Levantamentos Geológicos Básicos do Brasil - PLGB. Geologia e recursos minerais do Estado de Sergipe. Escala (1:250.000). Brasília: CPRM/DIEDIG/DEPAT; CODISE; 2001.

6. Teixeira LR. Mapa Geológico do Estado de Sergipe. Mapa Geológico, Escala 1:250.000. Sergipe: CPRM/CODISE; 2014.

7. Silva Filho M, Bomfim LFC, Santos RA, Leal RA, Santana AC, Filho PAB. Geologia da Geossinclinal Sergipana e do seu embasamento Alagoas, Sergipe e Bahia: Projeto Baixo São Francisco/Vaza Barris. Brasília: DNPM/CPRM; 1979. 134 p.

8. Carvalho MJ de. Evolução Tectônica do Domínio Marancó-Poço Redondo: Registro das Orogêneses Cariris Velhos e Brasiliana na Faixa Sergipana, NE do Brasil [thesis]. Campinas: Universidade Estadual de Campinas; 2005. 202 p.

9. Brito MFL de, Silva Filho AF da, Guimarães IP. Caracterização Geoquímica e Isotópica do Batólito Serra do Catu e sua evolução da interface dos domínios Sergipano e Pernambuco-Alagoas, Província Borborema. Revista Brasileira de Geociências. 2009;39(2):324-337.

10. Davison I, Santos RA. Tectonic Evolution of the Sergipano Fold Belt, NE Brasil, during Brasiliano Orogeny. Precambrian Research. 1989;45:319-342, doi:10.1016/0301-9268(89)90068-5.

11. Oliveira EP, Windley BF, Araújo MNC. The neoproterozoic Sergipano orogenic belt, NE Brazil: A complete plate tectonic cycle in western Gondwana. Precambriam Research. 2010;181:64-84, doi:10.1016/j.precamres.2010.05.014.

12. Gentil TFC. 2013. Petrologia e Geoquímica do Batólito Shoshonítico Serra do Brejo no Domínio Poço Redondo, Faixa Sergipana (Sul da Província Borborema). [dissertation]. São Cristóvão: Universidade Federal de Sergipe; 2013. 166 p.

13. Lisboa VAC. Petrologia e Geocronologia do Maciço Glória Norte, Faixa de Dobramentos Sergipana, NE do Brasil [dissertation]. São Cristóvão: Universidade Federal de Sergipe; 2014. 140 p.

14. Conceição JA. Petrologia do Stock Granítico Glória Sul, Faixa Sergipana, setor sul da Província Borborema, Sergipe [dissertation]. São Cristóvão: Universidade Federal de Sergipe; 2014. 145 p.

15. Oliveira ACS. Petrogênese do Stock Granítico Monte Alegre, nordeste do Domínio Macururé, Faixa Sergipana [dissertation]. São Cristóvão: Universidade Federal de Sergipe; 2014. 130 p.

16. Santos IS. Stock Granítico Propriá, Faixa Sergipana (NE-Brasil): Petrografia e Geoquímica [monografia]. São Cristóvão: Universidade Federal de Sergipe; 2014. 70 p.

17. Silva CC. Petrologia e Geocronologia do Stock Granodiorítico Lagoa do Roçado, Domínio Macururé, Faixa Sergipana-SE [dissertation]. São Cristóvão: Universidade Federal de Sergipe; 2014. 76p.

18. Le Maitre RW, Streckseisen A, Zanettin B, Le Bas MJ, Bonin B, Bateman P, et al. Igneous Rocks - A classification and glossary of terms. Recommendations of the International Union of Geological Sciences - Subcommission on the Systematics of Igneous Rocks. New York: Cambridge University Press; 2002. 254 p.

19. Janoušek V, Farrow CM, Erban V. Interpretation of Whole-rock Geochemical Data in Igneous Geochemistry: Introducing Geochemical Data Toolkit (GCDKit). Journal of Petrology. 2006 Jun;47(6):1255-1259, doi:10.1093/petrology/eg1013.

20. Conceição H. Os Granitos do Rio Caveira: Petrologia de Intrusões Pré-Cambrianas no Cisalhamento Axial do Complexo Contendas-Mirante (Bahia-Brasil) [dissertation]. Salvador: Universidade Federal da Bahia; 1986. $241 \mathrm{p}$.

21. Cox KG, Bell JD, Panknurst RJ. The interpretation of igneous rocks. 1st ed.: George Allen \& Unwin; 1979. $459 \mathrm{p}$.

22. Peccerillo A, Taylor SR. Geochemistry of Eocene Calc-Alkaline Volcanic Rocks form the Kastamonu Area, Northern Turkey. Contribution to Mineralogy and Petrology. 1976; 58:63-81, Doi: 10.1007/BF00384745.

23. Maniar PD, Piccoli PM. Tectonic discrimination of granitoids. Geological Society of American Bulletin. 1989;101:635-643, doi:10.1130/0016-7606(1989)101<0635:TDOG>2.3.CO;2. 
24. Pearce JA, Harris NBW, Tindle AG. Trace Elements Discrimination Diagrams for the Tectonic Interpretation of Granitic Rocks. Journal of Petrology. 1984;25:956-983. 